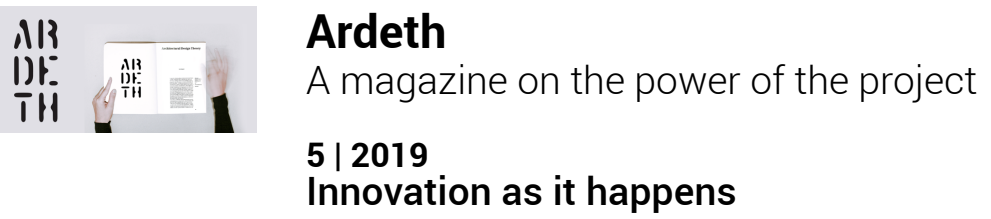

\title{
A Panoptic Cartography of Remote Sensing
}

\section{Marco Ferrari}

\section{(2) OpenEdition \\ Journals}

Electronic version

URL: http://journals.openedition.org/ardeth/366

ISSN: 2611-934X

Publisher

Rosenberg \& Sellier

Printed version

Date of publication: 1 November 2019

Number of pages: 132-142

ISSN: 2532-6457

\section{Electronic reference}

Marco Ferrari, «A Panoptic Cartography of Remote Sensing », Ardeth [Online], 5 | 2019, Online since 01 May 2020, connection on 18 November 2020. URL : http://journals.openedition.org/ardeth/366 


\title{
A Panoptic Cartography of Remote Sensing
}

\author{
Marco Ferrari
}

Abstract

Landsat has been the longest-running program dedicated to remote sensing ever initiated, regularly imagining Earth's landmasses since 1972. The distributed archive of data generated by the eight generations of satellites that followed one another in Low Earth orbit constitutes one of the largest collection of images in history; most of the imagery served by Google Earth to the screens of billions of its daily users is still based on Landsat products.

Looking at the history of Landsat - and exposing the early challenges around the acquisition, management and processing of data that the program had to face during its development - can be a productive way to question our current understanding of planetaryscale infrastructure and computation. The approach proposed by this project uses a series of visual props to advance literacy of geospatial data, and investigate the ways in which modernity's terrestrial imaginary has been shaped over the past few decades.
Affiliation Studio Folder, Agency for Visual Research

Contacts: marco [at] studiofolder [dot] it

Received: 03 December 2019

Accepted: 28 December 2019

DOI:

10.17454/ARDETH05.09 ARDETH\#05 
These dataacquisition

facilities generated

a distributed

archive of millions

of images that projected the

immateriality of

the information

generated in

orbit, into the

pattern of national

sovereignty.
On July 23, 1972, ERTS-1 ("Earth Resources Technology Satellite-1,” later known as Landsat-1) reached its destined sun-synchronous polar orbit on board a Delta 900 rocket. Two days later, the first cloud-free image acquired by its multispectral scanner system was developed into film, rendering a view over Ouachita Mountains in southeastern Oklahoma into a 80 meter-ground resolution image where lakes, rivers, mountain ranges and vegetation where clearly visible in their natural hues. Since then, at least one Landsat satellite has been continuously orbiting at an altitude between 900 and $700 \mathrm{~km}$ above Earth's surface: as the longest-running program dedicated to remote sensing, Landsat imagery constitutes a large part of Google Earth data at a regional scale, and is still taken as a benchmark to evaluate the accuracy of almost any other geospatial product.

The Landsat program raised early questions that remain central to the understanding of contemporary, planetary-scale infrastructure: by literally encompassing the whole planet under its sensors, it was designed to image Earth's landmasses recursively, in an attempt to detect any significative change of its environment; real-time processing of the vast amount of data it produced was not possibile onboard the spacecraft - and thus required a network of distributed ground stations (from the United States, to Saudi Arabia, to Australia) to download them while the satellite would transit above. These data-acquisition facilities generated a distributed archive of millions of images that projected the immateriality of the information generated in orbit (beyond the reach of any country's borders), into the pattern of national sovereignty while becoming one of the most politically-charged elements within the administration of the program. Issues about data sovereignty, such as the debate on the rights of sensing countries over sensed countries, led to the ratification of UN space treaties in the late 1970s and 1980s, and to the adoption in 1986 of the UN Principles Relating to Remote Sensing of the Earth from Outer Space.

In 2007, the introduction of the first iPhone made satellite imagery instantly available on a personal device, removing the need for any technical understanding of its production, and bringing the panoptic view of the satellite at the user's fingertips. The now 
familiar gesture of pinch-and-zoom (first demoed by Steve Jobs on stage of the Moscone Center in San Francisco, while zooming in on a slightly off-nadir image of the Washington Monument), embodies the way in which we navigate seamlessly across scales. Cartographic databases are used today by millions of people to move across familiar environments, plan long- or short-range trips, cross national borders, or reach shores of unknown countries in hope of a better life. They're the product of a global remote sensing apparatus made of spacecrafts, sensors, antennas, and fibre-optic cables, owned by nation states and private corporations, and managed through an intricate network of dataprocessing facilities. The different agendas of these institutions are concealed under the smooth, colour-corrected surface of commercial imagery, embedded in the metadata of the global digital mosaic like a footnote to the wonders of the contemporary geographic omniscience - while delivering a profitable picture of a borderless world. On the screen where the geographic information is delivered, all that counts is a smooth navigation experience: we can go everywhere - and we belong anywhere - on the evenly accessible surface criss-crossed by GPScalculated paths, where political and natural features are erased under the uniform roaming of a positioning dot.

This contemporary digital atlas - delivered on various platforms, and an integral part of any online query is still, though, an asynchronous composition of erratic resolutions, where the sharpness of most-populated areas decay into the algorithmically-interpolated gloom of high latitude coastlines and seabeds. This continuous, uncluttered view of the globe is achieved through the ceaseless stitching of hundreds of thousands images, at various scales and from a variety of sources.

Landsat, Copernicus, DigitalGlobe and Spot Image (just to name a few of these images' providers) all have constellations of specialised sensors that provide different combinations of resolution, light spectrum and periodicity between satellite overpasses. By looking at the data attribution's captions on Google Earth, Bing, or Apple Maps, it is possible to have a glimpse into the structure and rules of this intricate, tridimensional layering of commercial distribution
This contemporary digital atlas is still, though, an asynchronous composition of erratic resolutions, where the sharpness of mostpopulated areas decay into the algorithmicallyinterpolated gloom of high latitude coastlines and seabeds. 
agreements, where different image providers look at the Earth's surface from different altitudes and at different resolutions.

The virtual sky of Google Earth, Bing, or Apple Maps, through which we zoom in and out, pinching with our fingers, represents the ideal scenography for the assemblage of this mosaic. A perpetual, pale blue haze mediates the movement across scale, while a darker hue negotiates the transition between the highresolution domain of the land and the lesser-known digital elevations of the ocean's seabed. This sky is a contested space where different agendas are at play, and where only the exposure of the occasional digital artefact can provide a way to peer into the seams of its construction.

The research presented here, initially started as a participation to After Belonging, the 2016 Oslo Architecture Triennale, aims to become a platform for the construction of a new critical atlas, a spatial index of visual footnotes to the technical spaces that we cross while tapping on our screens.

The boundaries of these image products reflect national, military and commercial interests that need to be part of the understanding of the way in which our planet is imaged everyday. The series of visual props presented here are the first step towards visual and spatial literacy that is fundamental in an age of increasing prominence of geospatial information, and the pervasiveness of cartographic data in the fabric of our everyday lives. 


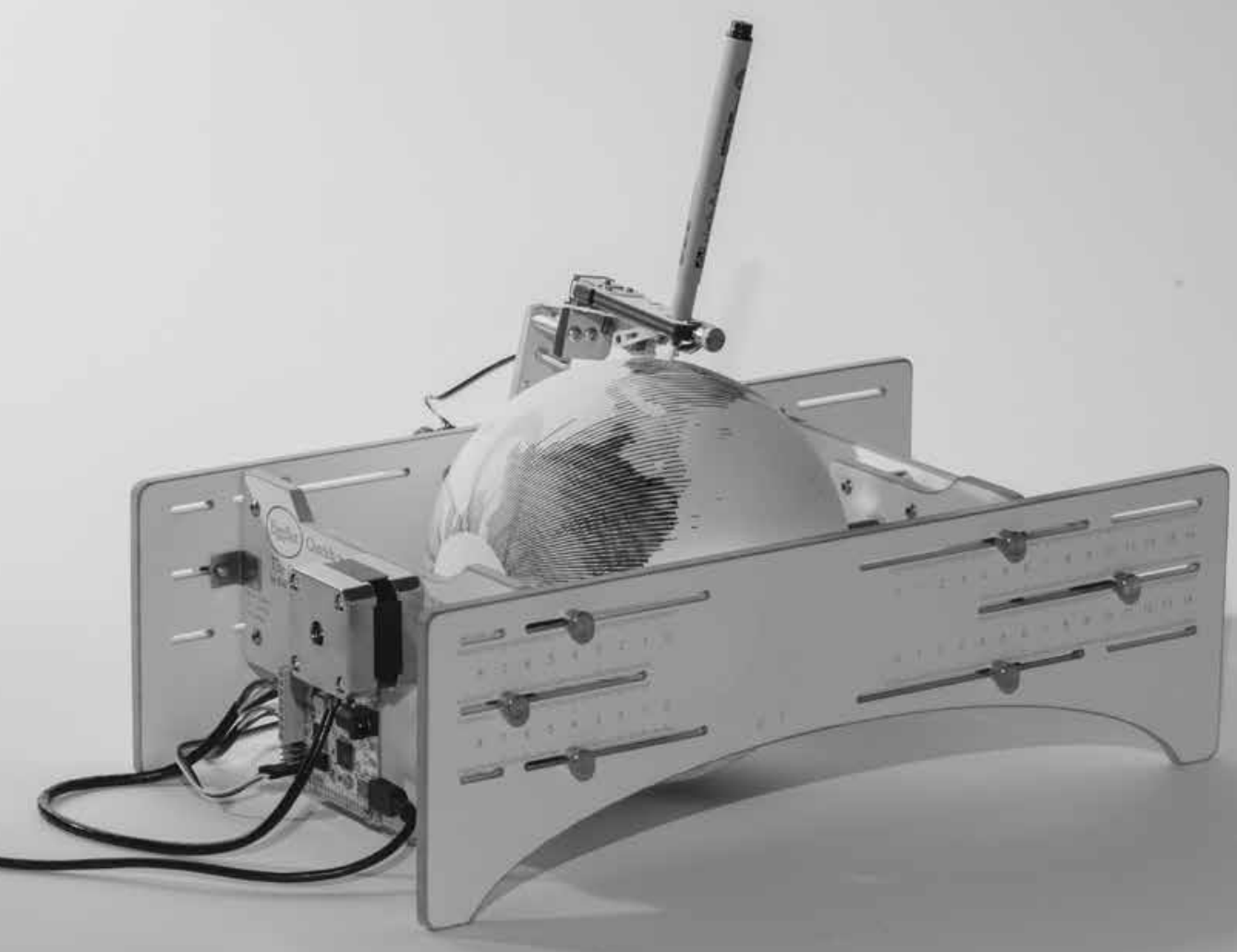

\section{Sensing}

The global mosaic produced by Landsat is far from an unfaltering panorama of the planet: in fact, it is composed of more than 60,000 images. The sensed areas vary hugely from year to year, according to a variety of reasons: needs for cartographic consolidation, weather conditions, environmental emergencies, technological compromises, military surveillance, political agenda, availability of ground receiving stations.

The sequence of maps presented here displays the amount and distribution of all the imagery collected by the Landsat programme between 1972 and 2016. All the publicly available Landsat datasets have been downloaded and parsed in order to produce a geographical representation of the imagery distribution over time, and translated into a series of maps. Each map represents the imagery available for a single year, through a visualisation of the satellite metadata along the actual Landsat orbital path, and plotted on a Space Oblique Mercator projection. A drawing machine has then been used to engrave the data onto globes, which had been previously crafted by hand through a custom process of casting and polishing. The thickness of the lines - which represents the number of photos available for a given year - is originated by the increasing vibration of the robot's arm, that hovers on the spinning globe while progressively drawing on it. 
Fig. 1 - Fig. 3 - The global mosaic produced by Landsat is far from an unfaltering panorama of the planet: in fact, it is composed of more than 60,000 images. The sensed areas vary hugely from year to year, according to a variety of reasons: needs for cartographic consolidation weather conditions, environmental emergencies, technological compromises, military surveillance, political agenda, availability of ground receiving stations. The sequence of maps presented here displays the amount and distribution of all the imagery collected by the Landsat programme between 1972 and 2016. All the publicly available Landsat datasets have been downloaded and parsed in order to produce a geographical representation of the imagery distribution over time, and translated into a series of maps. Each map represents the imagery available for a single year, through a visualisation of the satellite metadata along the actual Landsat orbital path, and plotted on a Space Oblique Mercator projection. A drawing machine has then been used to engrave the data onto globes, which had been previously crafted by hand through a custom process of casting and polishing. The thickness of the lines - which represents the number of photos available for a given year - is originated by the increasing vibration of the robot's arm, that hovers on the spinning globe while progressively drawing on it.

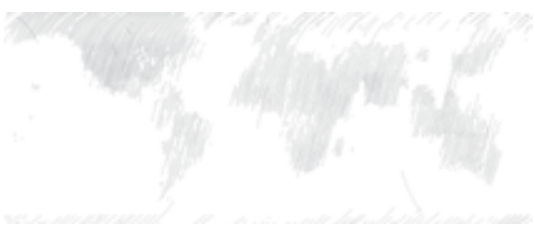

1972
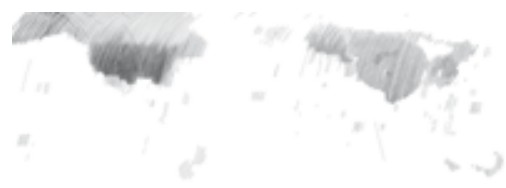

1977
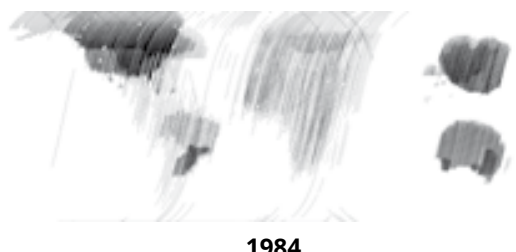

1984

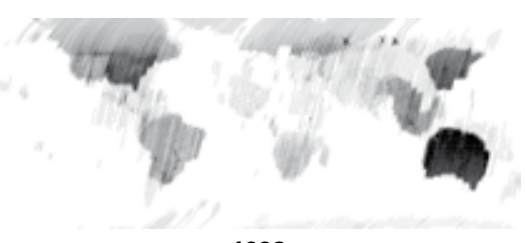

1992

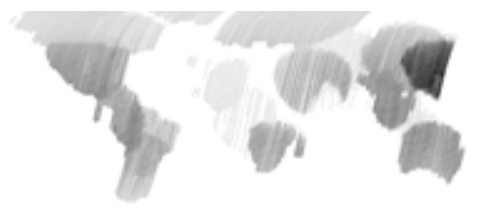

1998

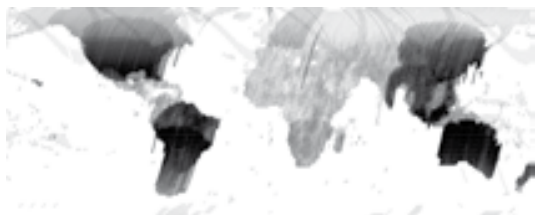

2004

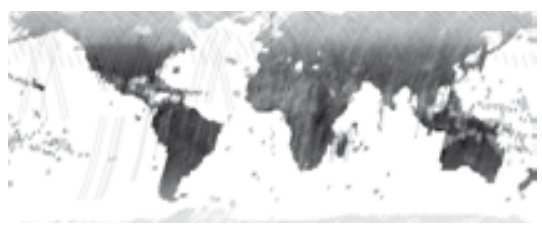

2013
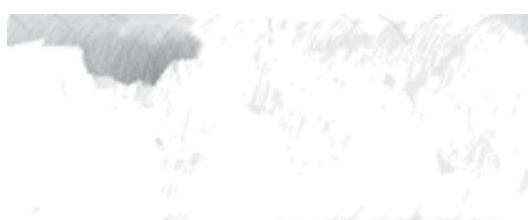

1974
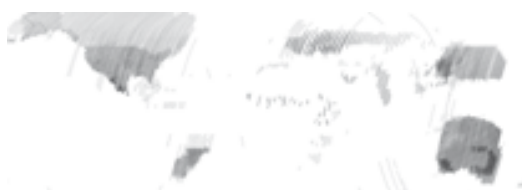

1981

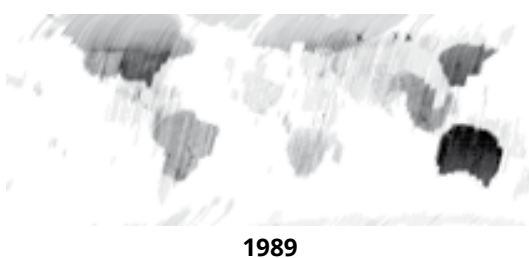

1989
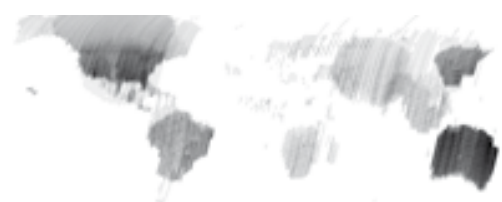

1995
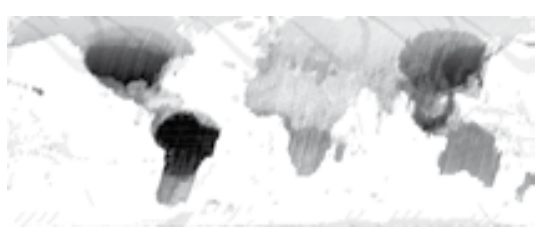

2001

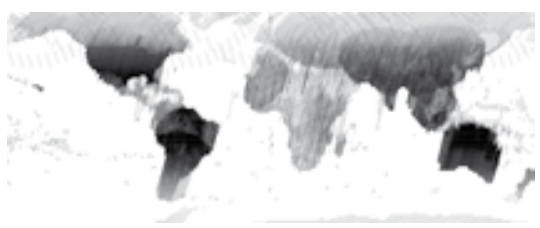

2009
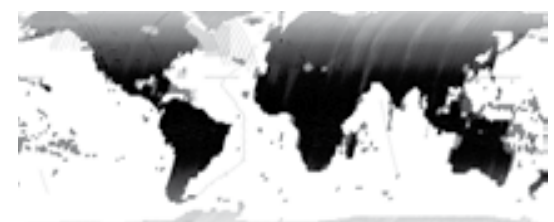

2016 

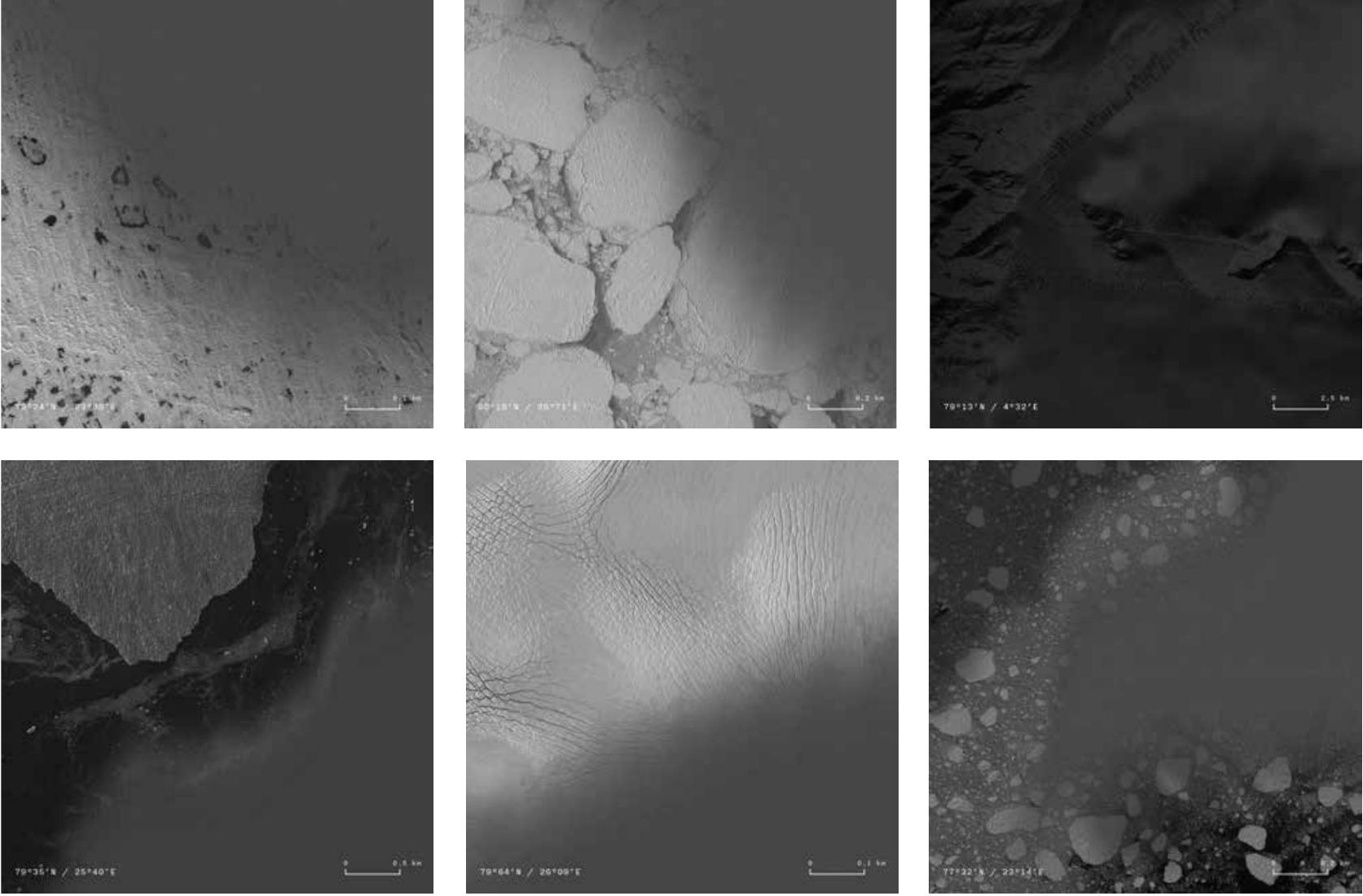

\section{Processing}

Svalbard is an archipelago situated between $74^{\circ} \mathrm{N}$ and $81^{\circ} \mathrm{N}$ in the Arctic Ocean. The Svalbard Treaty of 1920 recognises the full Norwegian sovereignty over the islands, but it guarantees equal access to their territory and resources to all the signatory nations. It also forbids any military operation on its land and waters. Mostly inhabited by mining workers from Russian and Norwegian origins during the XX century, Svalbard now hosts numerous advanced research outposts from a wide range of different nationalities. It's both a global research centre for the study of climate change and the upper atmosphere, and an emerging centrepiece of the new power race for influence and resources in the High Arctic. The ground station run by KSAT is the world's most important satellite control centre. Svalsat sits both at the centre and at the edge of the modern cartographic space: on one side, its latitude ensures the most optimal location to intercept polar-orbiting satellites; on the other, polar caps are very difficult to sense - it can take up to five years to have a fully updated mosaic of a region that would be otherwise covered by 10 Landsat scenes. The Svalbard archipelago offers a unique opportunity to investigate the production chain of the global geographic knowledge: by looking at it through a catalogue of the anomalies, fractures, and aberrations of the satellite imagery mosaic, one can read beyond the apparent smoothness of the charted globe. 


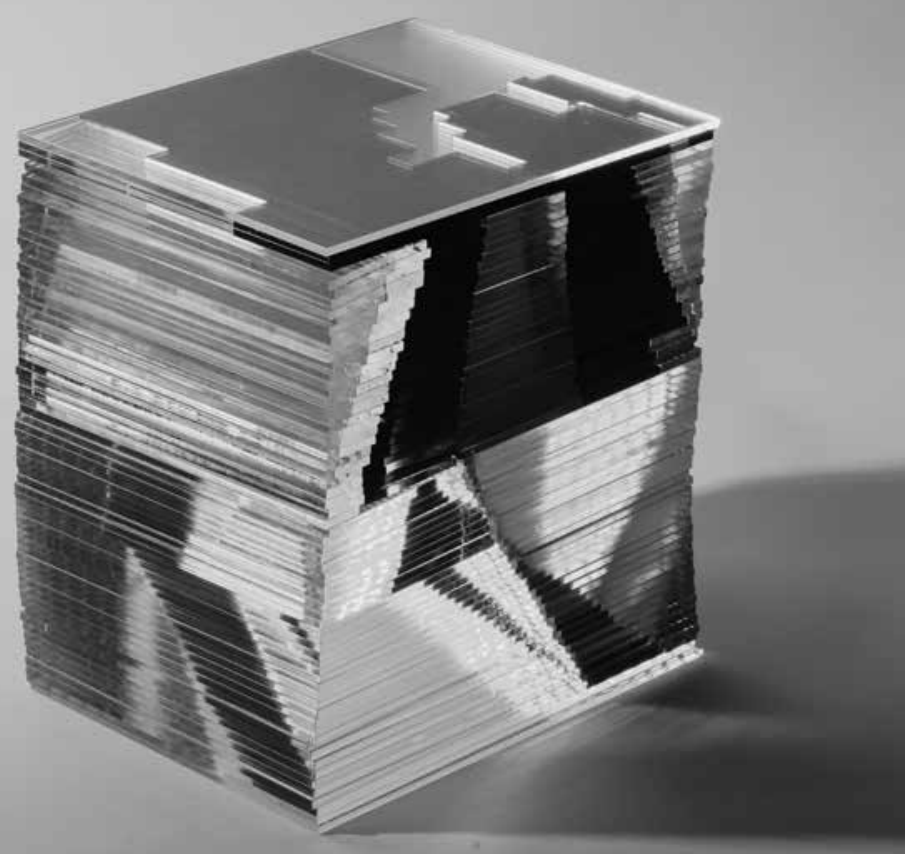

Rendering

Three models represent a vertical section through the Google Earth's sky above three sample locations: the territory of Svalbard, a high latitude area, where satellite scans are scarce and bordering tiles stretch over long periods of time; the contested border between Morocco and Western Sahara, a scarcely-populated region close to the Equator; the San Francisco Bay Area - one of the best mapped portions of the planet, and a usual testbed for commercial mapping services. Each layer represents a different zoom level, starting with a 1-square-km area on the bottom and progressing upwards by 500 -m intervals. The colours stand for different sources of satellite imagery.

"Uncharted - Footnotes to the Atlas" is a project by Studio Folder. Research and Design: Studio Folder (Marco Ferrari, Elisa Pasqual, Alessandro Busi, Pietro Leoni, Francesca Lucchitta, Giovanni Pignoni, Mariasilvia Poltronieri). / All photos by Mattia Balsamini, (C Studio Folder. 

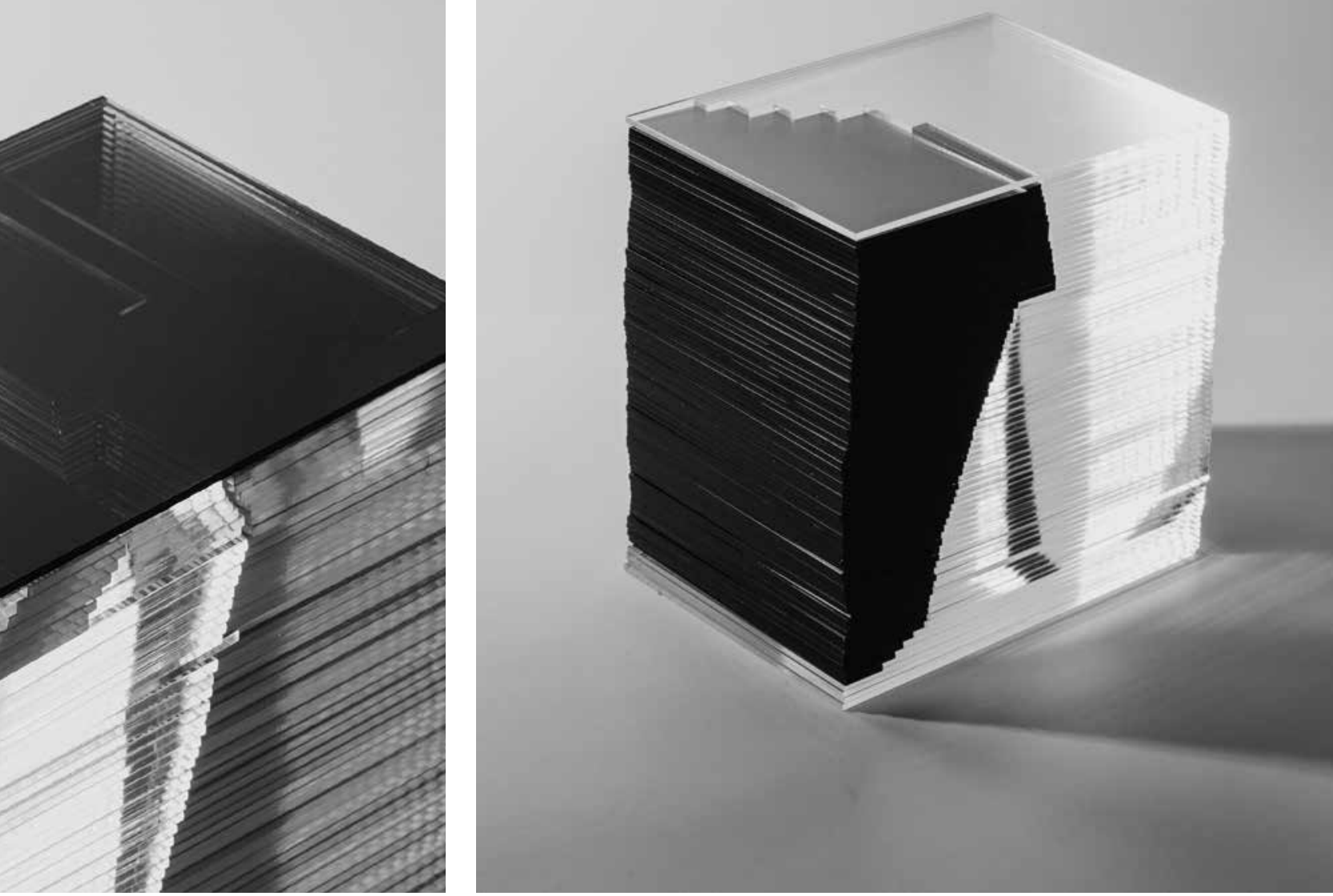

Fig. 5 - "Uncharted Footnotes to the Atlas", Detail of a model representing a vertical section through the satellite imagery of the Google Maps mosaic, as of September 2016. This visualisation analyses the cloudless, evenly-lit skies of Google's mapping services, exposing the variety of sources of the current global remote sensing apparatus. Model \#01, Svalbard Archipelago.
Fig. 6 - "Uncharted Footnotes to the Atlas", Detail of a model representing a vertical section through the satellite imagery of the Google Maps mosaic, as of September 2016. This visualisation analyses the cloudless, evenly-lit skies of Google's mapping services, exposing the variety of sources of the current global remote sensing apparatus. Model \#02, Western Sahara.
Fig. 7 - "Uncharted Footnotes to the Atlas", Detail of a model representing a vertical section through the satellite imagery of the Goog le Maps mosaic, as of September 2016. This visualisation analyses the cloudless, evenly-lit skies of Google's mapping services, exposing the variety of sources of the current global remote sensing apparatus. Model \#02, San Francisco Bay Area. 


\section{References}

Cosgrove, D. (2003), Apollo's Eye: A Cartographic Genealogy of the Earth in the Western Imagination, Baltimore, The Johns Hopkins University Press.

Gabrynowicz, J. I. (ed.), (2002), The UN Principles Relating to Remote Sensing of the Earth from Space: A Legislative History, Oxford, University of Mississippi School of Law.

Goward, S. N., Williams, D. L., Arvidson, T., Rocchio, L. E. P., Irons, J. R., Russell, C. A., Johnston, S. S. (2017), Landsat's Enduring Legacy: Pioneering Global Land Observations from Space, Bethesda, American Society for Photogrammetry and Remote Sensing.

Kurgan, L. (2013), Close Up at a Distance: Mapping, Technology, and Politics, New York, Zone Books. 
